\section{Potential limitations of a conical spacer device in severe asthma}

A conical spacer device (Nebuhaler, Astra) has been suggested as an alternative to a nebuliser for the delivery of bronchodilators in acute severe asthma ${ }^{1}$ and chronic stable asthma. ${ }^{2}$ When using the conical spacer coordination of inspiration with actuation of the metered dose aerosol is unnecessary as a one way valve closes on expiration, allowing aerosol in the $750 \mathrm{ml}$ reservoir to be inhaled over several breaths.

We describe a patient who failed to obtain relief from her terbutaline aerosol used through the conical spacer when her expiratory flow became too low to close the one way valve, thus allowing expired air to blow the aerosol out of the reservoir. We measured the flow rates necessary to close the valves on 10 conical spacers and examined the implications of our findings.

\section{Patient, method, and results}

A 35 year old woman with unstable asthma had been prescribed a conical spacer device to use with her terbutaline inhaler. Initially she obtained good symptomatic relief of her wheezing whenever she used the device. After several weeks her asthma deteriorated with severe morning wheeze which was unrelieved by terbutaline through the conical spacer. At these times her expiratory flow rates were too low to close the spacer valve and she therefore exhaled through the reservoir of the device (see figure). Terbutaline taken

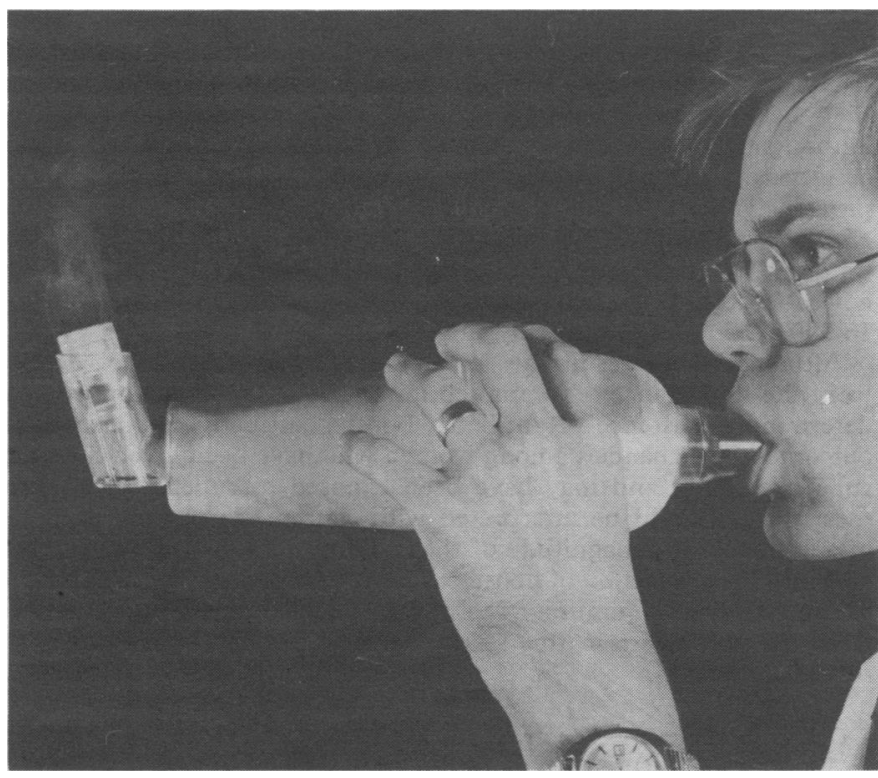

Simulation with solid $\mathrm{CO}_{2}$ of subject with low flow rate failing to close valve on expiration and blowing aerosol out of reservoir.

from the metered dose aerosol in the conventional manner, however, relieved her wheeze. When her wheezing was less severe she found that she could close the one way valve on the spacer and that again it gave symptomatic relief.

We examined the spacer and found that it was clean and working normally. We measured the flow rate of air that was necessary to close the valve on 10 separate manoeuvres in three positions-horizontal, at $45^{\circ}$ upwards, and at $45^{\circ}$ downwards-using a Morgan differentiating dry spirometer. We studied the patient's conical spacer and nine other identical devices.

When held horizontally, as illustrated by the manufacturers, a mean flow rate of $68 \mathrm{l} / \mathrm{min}$ (range 44-94) was needed to cause valve closure. When held upwards at $45^{\circ}$ a considerable increase in the flow rate was necessary to close the valve (mean $831 / \mathrm{min}$; range $67-94$ ). Conversely, when pointed downwards at $45^{\circ}$ nine of the 10 valves closed at zero flow.

\section{Comment}

A theoretical advantage of the conical spacer is that it provides a reservoir of aerosol that can be inhaled over several breaths through a one way valve. It is useful in asthmatics with low peak flow rates and small vital capacities who require several breaths from the reservoir to obtain maximum benefit. The one way valve must close to prevent patients breathing out through the reservoir and wasting the aerosol, as this case illustrates.
There are no published data on the flow rates required to close the spacer valves. Our findings suggest that peak flow rates present in severe asthmatic attacks may fail to close these valves, thus causing wastage of the aerosol. Undue reliance on the device in these circumstances might have serious consequences. To some extent this may be overcome by pointing the device downwards, allowing gravity to close the valve. The inability of a patient to close the valve on the spacer device, while being an indication of the severity of the asthmatic attack, may limit the clinical benefit that can be obtained from the conical spacer in severe asthma.

${ }^{1}$ Morgan MDL, Singh BV, Frame MH. Terbutaline aerosol given through pear spacer in acute severe asthma. $B r$ Med 7 1982;285:849-50.

${ }^{2}$ O'Reilly JF, Buchanan DR, Sudlow MF. Pressurised aerosol with conical spacer is an effective alternative to nebuliser in chronic stable asthma. Br Med F 1983;286:1548.

(Accepted 12 fanuary 1984)

Department of Respiratory Medicine, The London Hospital, Whitechapel, London E1 $1 \mathrm{BB}$

I D COX, MA, MRCP, Wellcome research fellow

P J W WALLIS, BSC, MRCP, Wellcome research fellow

M C P APPS, MA, MRCP, senior registrar

Correspondence to: Dr I D Cox, Tanglin Surgery, Sydney Road, Bordon, Hants GU35 0BL.

\section{Renal proximal dysfunction in patients with rheumatic diseases}

Although glomerular proteinuria is uncommon in early rheumatic diseases, it is a complication of advanced disease caused by the direct effects of the disease on the kidney or the action of nephrotoxic drugs, or both. ${ }^{12}$ Alterations in proximal tubular function may be a sensitive index of the reaction of the kidney to various toxic stimuli. ${ }^{3}$ This form of tubular dysfunction, which is shown by increasing amounts of protein of low molecular weight in the urine, cannot generally be detected by routine urine analysis. We report a study of proximal tubular function in 87 consecutive patients with severe arthritis admitted to a regional rheumatic disease centre.

\section{Patients, methods, and results}

A $10 \mathrm{ml}$ random sample of urine was collected from 87 patients ( 34 men, 53 women), of whom 43 had rheumatoid arthritis, 17 osteoarthrosis, nine ankylosing spondylitis, six seronegative polyarthritis, and 12 other diseases. The urine specimens were collected soon after admission, usually before the disease had been brought under control with drug treatment or physiotherapy. They were collected in the morning but not at a fixed time in relation to drug treatment as the patients were receiving a wide variety of drugs.

Urine samples were preserved with a thymol crystal and tested routinely with Albustix. In addition, the $\mathrm{pH}$ was measured, and concentrations of albumin, $\alpha_{1}$ microglobulin, and $\beta_{2}$ microglobulin were measured by single radial immunodiffusion using specific antisera and standards obtained from Behringwerke, Marburg, Germany ( $x_{1}$ microglobulin and albumin) and Dakopatts, Copenhagen ( $\beta_{2}$ microglobulin). All protein measurements were corrected for urinary creatinine concentration and expressed as $\mathrm{mg} / \mathrm{g}$ creatinine. Total urine protein concentrations were measured by nephelometry using the trichloroacetic acid microprecipitation method recommended for the measurement of total protein in cerebrospinal fluid (Hyland Laser nephelometer instrument application sheet).

Albustix testing showed that 24 of the 87 samples contained a trace of protein, seven showed $0.3 \mathrm{~g} / \mathrm{l}$, two showed $1.0 \mathrm{~g} / \mathrm{l}$, one showed $3 \mathrm{~g} / \mathrm{l}$, and the remainder gave negative results. The upper limit of normal urine $x_{1}$ microglobulin concentrations is $10 \mathrm{mg} / 1$ creatinine (mean (SD) $3(2.5) \mathrm{mg} / \mathrm{g}$ ); 30 of the 87 patients had concentrations higher than this (mean $33(24) \mathrm{mg} / \mathrm{g}$ ) creatinine (range $10-125 \mathrm{mg} / \mathrm{g}$ ). Urine $\beta_{2}$ microglobulin concentrations were raised in 12 patients $(>10 \mathrm{mg} / \mathrm{g}$ creatinine in eight); the upper limit of normal concentrations is $0.1 \mathrm{ng} / \mathrm{g}$ creatinine, which is too low for detection by radial immunodiffusion. Raised urine albumin concentrations $(>50 \mathrm{mg} / \mathrm{g}$ creatinine) were found in 15 patients, in five of whom albumin was the only protein at an abnormal concentration. Of the 35 patients who showed evidence of either proximal tubular dysfunction or increased urinary albumin excretion, only 18 had raised total protein concentrations ( $>150$ $\mathrm{mg} / \mathrm{g}$ creatinine) as measured by nephelometry.

Of the 21 patients with the most pronounced tubular dysfunction as shown by impaired reabsorption of low molecular weight proteins, whose mean 
age was 61.9 years, 15 had rheumatoid arthritis (duration three to 26 years), two seronegative polyarthritis, one ankylosing spondylitis, and three osteoarthritis. In this group the mean serum concentration of urea was $7.04 \mathrm{~mol} / \mathrm{l}(42 \mathrm{~g} / 100 \mathrm{ml}$ ) (normal range $2 \cdot 5-7 \cdot 5 \mu \mathrm{mol} / 1(15-45 \mu \mathrm{g} / 100 \mathrm{ml})$ ) and of creatinine $87.5 \mu \mathrm{mol} / 1(0.99 \mathrm{mg} / 100 \mathrm{ml}$ ) (normal range $50-140$ $\mu \mathrm{mol} / \mathrm{l}(0.6-1.6 \mathrm{mg} / 100 \mathrm{ml}))$. All these patients were taking at least two drugs: 12 were receiving a non-steroidal anti-inflammatory agent, 13 an analgesic, two sodium aurothiomalate, and four penicillamine. None was diagnosed as having amyloidosis.

\section{Comment}

In this group of patients with severe arthritis there was an unexpectedly high prevalence of renal proximal tubular dysfunction. A survey of 500 healthy adults showed tubular abnormality in under $1 \%{ }^{4}$ Tubular dysfunction as severe as that seen in this study has not previously been recognised in rheumatic diseases. Our results show that tubular dysfunction is not obviously specific to a disease or drug, although it may be more common in longstanding rheumatoid arthritis.

' Bacon PA, Hadler NM, eds. The kidney and rheumatic disease. London: Butterworth Scientific, 1982. (Butterworths International Medical Reviews. Rheumatology 1.)

2 Matthes KJ. Drug-induced proteinuria. In: Weise M, ed. Contributions to Nephrology Vol 24. Basle: Karger, 1980:109-14.

${ }^{3}$ Morgan DB. Assessment of renal tubular function and damage and their clinical significance. Anal Biochem 1982;190:307-13.

- Yu H, Yanagisawa Y, Forbes MA, Cooper EH, Crockson RA, MacLennan ICM. Alpha-1-microglobulin: an indicator protein for renal tubular function. F Clin Pathol 1983;36:253-9.

(Accepted 4 January 1984)

Clinical Pharmacology Unit of University of Leeds, Royal Bath Hospital, Harrogate HG1 2PS

H A BIRD, MD, MRCP, lecturer in rheumatology and consultant rheumatologist

Unit for Cancer Research of University of Leeds, Royal Bath Hospital

H YU, PHD, research fellow

E H COOPER, MD, FRCP, professor of cancer research

Correspondence to: Dr H A Bird.

\section{Protracted anuria due to active renal vasoconstriction in malignant hypertension}

Most renal lesions causing anuria in malignant hypertension are considered to be irreversible, but partial recovery of renal function has been reported in a few patients treated with maintenance haemodialysis. We report on a patient with malignant hypertension in whom two separate episodes of protracted anuria occurred.

\section{Case report}

A 27 year old black African man was admitted on 27 October 1976 with fever, epigastric pain, and diffuse joint pain. There was no relevant history. Physical examination yielded normal results. Blood pressure was $120 / 90$ $\mathrm{mm} \mathrm{Hg}$. Despite thorough investigations no cause was found for his condition, and tests for hepatitis $B$ surface antigen yielded negative results. Renal function was normal (serum creatinine concentration $100 \mu \mathrm{mol} / \mathrm{l}$ $(1.1 \mathrm{mg} / 100 \mathrm{ml})$; no proteinuria; and a normal intravenous pyelogram). After a month blood pressure suddenly rose to $180 / 130 \mathrm{~mm} \mathrm{Hg}$ and he became anuric. Serum creatinine concentration was $1100 \mu \mathrm{mol} / 1(13 \cdot 1 \mathrm{mg} / 100$ $\mathrm{ml}$.

He was admitted to this renal unit on 11 December and immediately treated with haemodialysis, propranolol, and dihydralazine (figure). On 14 December percutaneous renal biopsy showed ischaemic glomeruli, interstitial oedema, flattened and aplastic tubular epithelium, and fibroelastic endarteritis without fibrinoid necrosis of the vessel walls or thrombosis. The internal elastic laminas were intact. Immunofluorescence testing yielded negative results. On 22 December, renal arteriography showed total interruption of the blood flow to the cortex and medulla. Only the main branches of the renal artery were opacified. A few vessels reached some areas of the deep cortex. They showed an abnormal pattern and appeared beaded. Cortical nephrography was not done. There were no microaneurysms. Biopsies of muscle and the sural nerve did not show angiitis. Because of persistent anuria with poorly controlled high renin activity $(3.0 \mathrm{nmol} / \mathrm{l} / \mathrm{h}$ $(3.9 \mathrm{ng} / \mathrm{ml} / \mathrm{h})$; normal $0.5-1.0 \mathrm{nmol} / \mathrm{l} / \mathrm{h}(0.6-1.3 \mathrm{ng} / \mathrm{ml} / \mathrm{h})$ ) and hypertension we removed one of his kidneys on 1 March 1977 in preparation for future renal transplantation. Renal pathological examination again showed mildly damaged vessels with only irregular hyaline arteriolar deposits, ischaemic glomeruli, and atrophic tubules without necrosis or tubulorrhexis. Immunofluorescence testing yielded negative results. Over the following weeks urine output increased progressively and the serum creatinine concentration decreased to $600 \mu \mathrm{mol} / 1(6.6 \mathrm{mg} / 100 \mathrm{ml})$. Haemodialysis was stopped on 4 April. Creatinine clearance was $19 \mathrm{ml} / \mathrm{min}$.

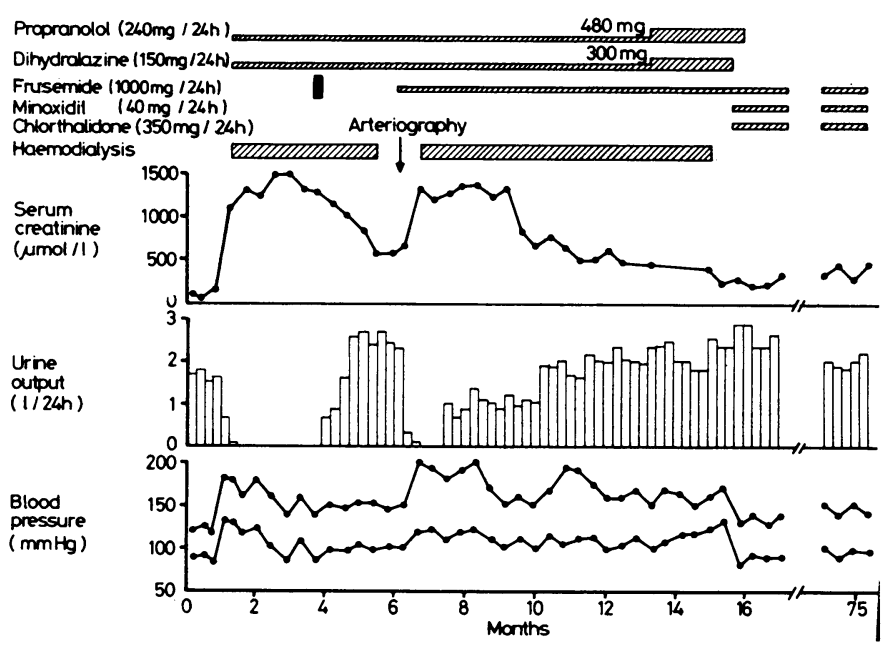

Clinical findings and treatment in patient with malignant hypertension who experienced two separate episodes of anuria.

Conversion: SI to traditional units-Creatinine: $1 \mu \mathrm{mol} / 1 \approx 11 \cdot 3 \mu \mathrm{g} / 100 \mathrm{ml}$.

On 4 May renal arteriography showed considerable improvement. The renal cortical vasculature was again visible, and the contrast medium reached the outer aspect of the kidney, although the small calibre vessels still showed an abnormal pattern. Immediately afterwards renal function deteriorated and he was again treated with haemodialysis. Control of blood pressure was particularly difficult. Renal function progressively improved, and dialysis was stopped on 1 February 1978. Blood pressure was controlled with a combination of high dosage minoxidil, frusemide, and chlorthalidone. He was followed up regularly, and in April 1983 his blood pressure was 150/100 $\mathrm{mm} \mathrm{Hg}$ with creatinine clearance stable at $30 \mathrm{ml} / \mathrm{min}$.

\section{Comment}

Over the past 10 years several workers have reported on patients with malignant hypertension and complete anuria who recovered enough renal function to allow haemodialysis to be stopped.1-3 The improvement of renal function was generally correlated with control of blood pressure with $\beta$ blockers and vasodilators, especially minoxidil. ${ }^{2}$ The reports do not suggest the mechanism of protracted anuria, and few angiographic data are available. In our patient initial renal arteriography and renal histological investigation showed the discrepancy between complete interruption of renal cortical flow and the absence of major arterial and arteriolar lesions. Thus the anuria was mainly due to extreme renal vasoconstriction without the formation of irreversible lesions despite virtual absence of kidney perfusion. The improvement in renal function was due to the restoration of blood flow to the cortex rather than to the healing of vascular damage with appropriate antihypertensive treatment. ${ }^{4}$ This type of renal shut down is similar to functional renal failure in patients with cirrhosis, which is also due to active renal vasoconstriction. ${ }^{5}$

Reversible anuria in malignant hypertension represents a particular subset of chronic and functional rather than acute and organic renal failure.

${ }^{1}$ Cordingley FT, Jones NF, Wing AJ, Hilton PJ. Reversible renal failure in malignant hypertension. Clin Nephrol 1979;109:98-103.

2 Luft FC, Bloch R, Szwed JJ, Grim CM, Grim CE. Minoxidil treatment of malignant hypertension. Recovery of renal function. $\mathcal{F} A M A 1978$; $240: 1985-7$.

${ }^{3}$ Mamdani BH, Lim US, Mahurkar SD, Katz AI, Dunea G. Recovery from prolonged renal failure in patients with accelerated hypertension. $N$ Engl F Med 1974 ;291 : 1343-4. 